Research Paper

\title{
Correlation between genetic polymorphism of angiopoietin-2 gene and clinical aspects of rheumatoid arthritis
}

Chengqian Dai1”, Shu-Jui Kuo ${ }^{2,3 \#, ~ J i n ~ Z h a o 4, ~ L u l u ~ J i n, ~ L e ~ K a n g 4, ~ L i h o n g ~ W a n g ~}{ }^{1}$, Guohong Xu1, Chih-Hsin Tang $2,5,6 \bowtie$, Chen-Ming Su ${ }^{\llbracket}$

1. Department of Orthopedics, Affiliated Dongyang Hospital of Wenzhou Medical University, Dongyang, Zhejiang, China

2. School of Medicine, China Medical University, Taichung, Taiwan

3. Department of Orthopedic Surgery, China Medical University Hospital, Taichung, Taiwan

4. Department of Biomedical Sciences Laboratory, Affiliated Dongyang Hospital of Wenzhou Medical University, Dongyang, Zhejiang, China

5. Chinese Medicine Research Center, China Medical University, Taichung, Taiwan

6. Department of Biotechnology, College of Health Science, Asia University, Taichung, Taiwan

\# These authors have contributed equally to this work

$\triangle$ Corresponding authors: Chen-Ming Su, PhD., Department of Biomedical Sciences Laboratory, Affiliated Dongyang Hospital of Wenzhou Medical University. E-mail: ericsucm@163.com. Chih-Hsin Tang, PhD. E-mail: chtang@mail.cmu.edu.tw

(C) Ivyspring International Publisher. This is an open access article distributed under the terms of the Creative Commons Attribution (CC BY-NC) license (https://creativecommons.org/licenses/by-nc/4.0/). See http://ivyspring.com/terms for full terms and conditions.

Received: 2018.10.11; Accepted: 2018.12.07; Published: 2019.01.01

\begin{abstract}
The Angiopoietin-2 (Ang2) gene encodes angiogenic factor, and the polymorphisms of Ang2 gene predict risk of various human diseases. We want to investigate whether the single nucleotide polymorphisms (SNPs) of the Ang2 gene can predict the risk of rheumatoid arthritis (RA). Between 2016 and 2018, we recruited 335 RA patients and 700 control participants. Comparative genotyping for SNPs rs2442598, rs734701, rs 1823375 and rs 12674822 was performed. We found that when compared with the subjects with the A/A genotype of SNP rs2442598, the subjects with the T/T genotype were 1.78 times likely to develop RA. The subjects with C/C genotype of SNP rs734701 were 0.53 times likely to develop RA than the subjects with TT genotype, suggesting the protective effect. The subjects with G/G genotype of SNP rs 1823375 were 1.77 times likely to develop RA than the subjects with $C / C$ genotype. The subjects with $\mathrm{A} / \mathrm{C}$ and $\mathrm{C} / \mathrm{C}$ genotype of SNP rs 11137037 were 1.65 and 2.04 times likely to develop RA than the subjects with A/A genotype. The subjects with G/T and T/T genotype of SNP rs 12674822 were 2.42 and 2.25 times likely to develop RA than the subjects with $\mathrm{G} / \mathrm{G}$ genotype. The $T$ allele over $\mathrm{rs} 734701$ can lead to higher serum erythrocyte sedimentation rate level $(p=0.006)$. The A allele over rs 11137037 was associated with longer duration between disease onset and blood sampling $(p=0.003)$. Our study suggested that Ang2 might be a diagnostic marker and therapeutic target for RA therapy. Therapeutic agents that directly or indirectly modulate the activity of Ang2 may be the promising modalities for RA treatment.
\end{abstract}

Key words: Angiopoietin-2; single nucleotide polymorphisms; rheumatoid arthritis

\section{Introduction}

Rheumatoid arthritis (RA) is manifested by marked hypertrophy, hypervascularity of the synovial tissues and consequent joint destruction, plaguing around $1 \%$ of the global population $[1,2]$. Despite the recent advent of biological agents enabling some RA patients to achieve disease remission with minimal symptoms, a marked proportion of patients remain treatment-refractory and suffer from progressive joint destruction, functional deterioration or even premature mortality [3-5]. The fact that genetic factors account for about $60 \%$ of the overall susceptibility to RA highlights the importance of research into genetic aberrations of this disease [3, 6-8]. Investigations into RA genetics could facilitate risk prediction for individual patients and facilitate personalized regimen. 
Single nucleotide polymorphisms (SNPs) denote the single nucleotide variations occurring at specific sites in the genome with substantial frequency within the population [1, 9, 10]. Genotyping SNPs and comparing the frequency of SNPs among subgroups (e.g., controls and patients) are frequently utilized to examine the risk and prognosis of human, including RA $[6,10,11]$.

The process of angiogenesis is pivotal in the pathogenesis of RA. The proliferation of the synovial lining of joints and the subsequent invasion by the pannus of underlying cartilage and bone necessitate an increase in the vascular supply to the synovium in RA [12-14]. Angiogenesis is also essential in facilitating the invasion of inflammatory cells and increase in local pain receptors that contribute to structural damage and pain. The angiogenic process is further modulated by the complex interplays between various mediators such as growth factors, notably vascular endothelial growth factor (VEGF) and the angiopoietin 2 (Ang2) [15-18].

The angiopoietin family mediates the process of angiogenesis and has two main members. Angiopoietin-1 is critical for vascular maturation, adhesion, migration, and survival. Ang2 promotes cell death and disrupts vascularization in its singular form but enhances angiogenesis in conjunction with VEGF [19]. The VEGF/Ang2-induced angiogenesis modulates RA-associated angiogenic processes [16]. The genetic polymorphisms of Ang2 harbor prognostic values for various human disease, including retinopathy, lung diseases and secondary lymphedema after breast cancer surgery [17, 20, 21]. Despite the known impact of Ang2 on RA pathogenesis and the recognized prognostic value of Ang2 SNPs for human disease, little is known about the association between Ang2 SNPs and the risk of RA. In this study, we tried to determine the predictive capacity of Ang2 SNPs as candidate biomarkers for susceptibility to RA.

\section{Materials and Methods}

\section{Patients and blood samples}

We collected 335 blood specimens from the patients who had been diagnosed with RA at Dongyang People's Hospital as the RA group from 2016 to 2018. For the control group, 700 health participants without RA history or cancers were enrolled. All of the participants provided written informed consent, and this study was approved by the Ethics Committee of Dongyang People's Hospital Ethics Committee and Institutional Review Board (2016-YB002). Clinical and pathological characteristics of all patients were determined based on medical records. A standardized questionnaire and electronic medical record system were used to acquire detailed clinical data on age, sex and disease duration, as well as concurrent treatment with methotrexate, prednisolone, and tumor necrosis factor- $\alpha$ (TNF- $\alpha$ ) inhibitors. At baseline, serum samples were collected from all RA patients and analyzed for the level of anti-citrullinated protein antibodies (ACPAs), rheumatoid factor (RF), erythrocyte sedimentation rate (ESR), and C-reactive protein (CRP). Samples were ACPA-positive if anti-CCP2 titers were $\geq 17$ $\mathrm{IU} / \mathrm{mL}$ and RF-positive if IgM RF titers were $\geq 30$ $\mathrm{IU} / \mathrm{mL}$. Whole blood samples $(3 \mathrm{~mL})$ were collected from all study participants and stored at $-80{ }^{\circ} \mathrm{C}$ for subsequent DNA extraction.

\section{Selection of Ang-2 polymorphisms}

Five Ang-2 SNPs were selected from the intron of Ang-2; all SNPs had minor allele frequencies of greater than 5\%. Most Ang-2 SNPs were known to be associated with lung injury or secondary lymphedema after breast cancer surgeries [21, 22].

\section{Genomic DNA extraction}

Genomic DNA was extracted from peripheral blood leukocytes using a QIAamp DNA blood kit (Qiagen, CA, USA) according to the manufacturer's instructions. Extracted DNA was stored at $-20^{\circ} \mathrm{C}$ and prepared for genotyping by polymerase chain reaction (PCR).

\section{Genotyping by real-time PCR}

Total genomic DNA was isolated from whole blood specimens using QIAamp DNA blood mini kits (Qiagen, Valencia, CA), following the manufacturer's instructions. DNA was dissolved in TE buffer $(10 \mathrm{mM}$ Tris $\mathrm{pH} 7.8,1 \mathrm{mM}$ EDTA) and stored at $-20^{\circ} \mathrm{C}$ until quantitative PCR analysis. Five Ang-2 SNP probes were purchased from Thermo Fisher Scientific Inc. (USA), and assessment of allelic discrimination for Ang-2 SNPs was conducted using a QuantStudio ${ }^{\mathrm{TM}} 5$ Real-Time PCR system (Applied Biosystems, CA, USA), according to the manufacturer's instructions. Data were further analyzed with QuantStudio ${ }^{\mathrm{TM}}$ Design \& Analysis Software (Applied Biosystems), and compiled statistics with clinical data [6]. Genotyping PCR was carried out in a total volume of $10 \mu \mathrm{L}$, containing 20-70 ng genomic DNA, $1 \mathrm{U}$ Taqman Genotyping Master Mix (Applied Biosystems, Foster City, CA, USA), and $0.25 \mu \mathrm{L}$ probes. The sequence of four Ang2 SNP probes were described as follows: rs2442598, TATGTGTGCGA GGACAGTGTGTGTT[A/T]ATTTTGTCCTCTTCTTG ATGGTTGA; rs734701, TGTGATATTGTGGAAAG ACCTGGTA[T/C]TCAAGTAATTTGTTATTCTATT 
CTC; rs1823375, GTGACTTCTCTTAGGGAGCACA CTT[C/G]CCTTCACCTGCCCTGACCACATGGA; rs11137037, CCCACCATCCCCCATTGCATGCCC T[A/C]AGCAAAGATACTCGTTTTGTGTTTC; rs12674822, GCAATCACTTGTCTGGCCCAACCC T[G/T]TATATTATTTGAGGCCCAGAAAAGG. The protocol included an initial denaturation step at $95^{\circ} \mathrm{C}$ for $10 \mathrm{~min}$, followed by 40 cycles of $95^{\circ} \mathrm{C}$ for $15 \mathrm{~s}$ and $60^{\circ} \mathrm{C}$ for $1 \mathrm{~min}[23,24]$.

\section{Statistical analysis}

Differences between the two groups were considered significant if $p$ values were less than 0.05 . Hardy-Weinberg equilibrium (HWE) was assessed using chi-square goodness-of-fit tests for biallelic markers. Since the data was independent and normal distribution, Fisher's exact test was used to compare differences in demographic characteristics between healthy controls and patients with RA. The odds ratios (ORs) and 95\% confidence intervals (CIs) for associations between genotype frequencies and the risk of RA or clinical and pathological characteristics were estimated by multiple logistic regression models, after controlling for other covariates. All data were analyzed using Statistical Analytic System software (v. 9.1, 2005; SAS Institute, Cary, NC, USA).

\section{Results}

All of the enrolled participants were identified as Chinese Han ethnicity. The mean age was $56.16 \pm$ 12.31 years old for the RA cohort and $43.60 \pm 17.85$ years old for the control cohort $(p<0.001)$. The proportion of female subjects was $82.7 \%$ in the RA cohort and $51.3 \%$ for the control cohort $(p<0.001)$. The interval between the onset of RA and the blood sampling was $71.36 \pm 91.45$ months. At the time of blood sampling, $39.4 \%$ of the RA cohort were receiving TNF- $\mathrm{a}$ inhibitors, $49.3 \%$ were receiving methotrexate, and $53.4 \%$ were receiving prednisolone. The majority of RA patients were rheumatoid factor (RF) positive $(84.2 \%)$ and anti-citrullinated protein antibody (ACPA) positive $(80.9 \%)$ (Table 1$)$. To mitigate the possible impact of confounding variables, AORs with $95 \%$ CIs were estimated by multiple logistic regression models after controlling for age in each comparison.

The details of polymorphism frequencies in both cohorts are shown in Table 2. All genotypes were in Hardy-Weinberg equilibrium $(p>0.05)$. The most frequent genotypes for SNPs rs2442598, rs734701, rs1823375 and rs12674822 in both groups were A/T, $\mathrm{T} / \mathrm{C}, \mathrm{C} / \mathrm{C}$ and $\mathrm{G} / \mathrm{T}$ respectively. The genotypes of highest frequency for rs 11137037 were AC for RA cohort and AA for control cohort.
Table 1. Comparison of demographic characteristics and clinical parameters of 700 healthy controls and 335 patients with RA.

\begin{tabular}{|c|c|c|c|}
\hline Variable & $\begin{array}{l}\text { Controls } \\
\mathrm{N}=700(\%)\end{array}$ & $\begin{array}{l}\text { RA Patients } \\
\text { N=335 (\%) }\end{array}$ & p value \\
\hline Age (y) & $\begin{array}{l}\text { Mean } \pm \text { S.D. } \\
43.60 \pm 17.85\end{array}$ & $\begin{array}{l}\text { Mean } \pm \text { S.D. } \\
56.16 \pm 12.31\end{array}$ & $\mathrm{p}<0.001$ \\
\hline \multicolumn{4}{|l|}{ Gender } \\
\hline Female & 359 (51.3) & $277(82.7)$ & \\
\hline Male & $341(48.7)$ & $58(17.3)$ & $\mathrm{p}<0.001$ \\
\hline \multicolumn{4}{|c|}{ RA duration (months) } \\
\hline & & $71.36 \pm 91.45$ & \\
\hline \multicolumn{4}{|c|}{ Serum CRP (mg/L) } \\
\hline & & $21.39 \pm 68.37$ & \\
\hline \multicolumn{4}{|l|}{$\operatorname{ESR}(\mathrm{mm} / \mathrm{h})$} \\
\hline & & $32.65 \pm 25.71$ & \\
\hline \multicolumn{4}{|l|}{ RF status } \\
\hline Negative & & $53(15.8)$ & \\
\hline Positive & & $282(84.2)$ & \\
\hline \multicolumn{4}{|l|}{ ACPA status } \\
\hline Negative & & $64(19.1)$ & \\
\hline Positive & & $271(80.9)$ & \\
\hline \multicolumn{4}{|c|}{ Anti-TNF drugs use } \\
\hline Non-users & & $203(60.6)$ & \\
\hline Current users & & $132(39.4)$ & \\
\hline \multicolumn{4}{|c|}{ Methotrexate use } \\
\hline Non-users & & $170(50.7)$ & \\
\hline Current users & & $165(49.3)$ & \\
\hline \multicolumn{4}{|c|}{ Prednisolone use } \\
\hline Non-users & & $156(46.6)$ & \\
\hline Current users & & $179(53.4)$ & \\
\hline
\end{tabular}

The Mann-Whitney U test or Fisher's exact test was used to compare values between controls and patients with RA. RA = rheumatoid arthritis; $y=$ years; S.D. = standard deviation; $\mathrm{CRP}=\mathrm{C}$-reactive protein; $\mathrm{ESR}=$ erythrocyte sedimentation rate; $\mathrm{RF}=$ rheumatoid factor; $\mathrm{ACPA}=$ anti-citrullinated protein antibodies; $\mathrm{TNF}=$ tumor necrosis factor.

When compared with the subjects with the A/A genotype of SNP rs2442598, the subjects with the T/T genotype were 1.78 times likely to develop RA (AOR $1.78 ; 95 \%$ CI 1.17 to 2,$71 ; p<0.05)$. The subjects with C/C genotype of SNP rs734701 were 0.53 times likely to develop RA (AOR 0.53; 95\% CI 0.34 to $0.83 ; p<0.05$ ) than the subjects with $\mathrm{T} / \mathrm{T}$ genotype. The subjects with G/G genotype of SNP rs1823375 were 1.77 times likely to develop RA (AOR 1.77; 95\% CI 1.12 to 2.79; $p<0.05)$ than the subjects with $\mathrm{C} / \mathrm{C}$ genotype. The subjects with $\mathrm{A} / \mathrm{C}$ and $\mathrm{C} / \mathrm{C}$ genotype of SNP rs11137037 were 1.65 (AOR 1.65; 95\% CI 1.19 to 2.29; $p<0.05$ ) and 2.04 (AOR 2.04; 95\% CI 1.37 to 3.04; $p<0.05)$ times likely to develop RA than the subjects with A/A genotype. The subjects with $\mathrm{G} / \mathrm{T}$ and $\mathrm{T} / \mathrm{T}$ genotype of SNP rs12674822 were 2.42 (AOR 2.42; 95\% CI 1.67 to 3.51; $\mathrm{p}<0.05$ ) and 2.25 (AOR 2.25; 95\% CI 1.48 to $3.42 ; \mathrm{p}<0.05)$ times likely to develop RA than the subjects with GG genotype.

The respective SNPs were all analyzed for their correlation with the demographic characteristics and clinical parameters. The T allele over the rs12674822 site was associated with 1.36 (AOR 1.36; 95\% CI 1.00 to $1.85 ; p<0.05$ ) times the likelihood to require steroid use than the $G$ allele (Table 3). The $T$ allele over rs734701 can lead to higher serum ESR level ( $p=$ 0.006) (Table 4). The A allele over rs11137037 was 
associated with longer duration between disease onset and blood sampling ( $p=0.003$ ) (Table 5).

Table 2. Comparison of the genotype and allele frequencies of the Ang2 polymorphism in 700 controls and 335 patients with RA.

\begin{tabular}{|c|c|c|c|c|}
\hline Variable & $\begin{array}{l}\text { Controls } \\
\mathrm{N}=700(\%)\end{array}$ & $\begin{array}{l}\text { Patients } \\
\mathrm{N}=335 \text { (\%) }\end{array}$ & $\begin{array}{l}\text { OR } \\
(95 \% \mathrm{CI})\end{array}$ & $\begin{array}{l}\text { AOR } \\
(95 \% \text { CI })\end{array}$ \\
\hline \multicolumn{5}{|l|}{ rs2442598 } \\
\hline AA & $205(29.3)$ & $93(27.8)$ & 1.00 (reference) & 1.00 (reference) \\
\hline AT & $364(52.0)$ & $151(45.1)$ & $0.941(0.671-1.247)$ & $0.970(0.687-1.369)$ \\
\hline TT & 131 (18.7) & $91(27.2)$ & $1.531(1.065-2.201)^{*}$ & $1.781(1.172-2.708)^{*}$ \\
\hline $\mathrm{AT}+\mathrm{TT}$ & 495 (70.7) & $242(72.3)$ & $1.078(0.807-1.439)$ & $1.170(0.845-1.620)$ \\
\hline A allele & 774 (55.3) & $337(50.3)$ & 1.00 (reference) & 1.00 (reference) \\
\hline $\begin{array}{l}\mathrm{T} \text { allele } \\
\text { rs734701 }\end{array}$ & $626(44.7)$ & $333(49.7)$ & $1.222(1.016-1.469)^{*}$ & $1.302(1.059-1.600)^{*}$ \\
\hline TT & $211(30.1)$ & $104(31.0)$ & 1.00 (reference) & 1.00 (reference) \\
\hline TC & 321 (45.9) & $182(54.3)$ & $1.150(0.855-1.548)$ & $1.168(0.839-1.626)$ \\
\hline CC & $168(24.0)$ & $49(14.6)$ & $0.592(0.398-0.879)^{*}$ & $0.527(0.337-0.825)^{*}$ \\
\hline $\mathrm{TC}+\mathrm{CC}$ & $488(69.9)$ & $231(68.9)$ & $0.958(0.723-1.271)$ & $0.947(0.691-1.296)$ \\
\hline $\mathrm{T}$ allele & $743(53.1)$ & $390(58.2)$ & 1.00 (reference) & 1.00 (reference) \\
\hline $\begin{array}{l}\text { C allele } \\
\text { rs1823375 }\end{array}$ & $657(46.9)$ & $280(41.8)$ & $0.812(0.674-0.978)^{*}$ & $0.784(0.637-0.965)^{*}$ \\
\hline $\mathrm{CC}$ & $345(49.3)$ & $149(44.5)$ & 1.00 (reference) & 1.00 (reference) \\
\hline CG & $289(41.3)$ & $138(41.2)$ & $1.106(0.836-1.462)$ & $1.192(0.870-1.633)$ \\
\hline GG & $66(9.4)$ & $48(14.3)$ & $1.684(1.108-2.559)^{*}$ & $1.769(1.121-2.794)^{*}$ \\
\hline$C G+G G$ & $355(50.7)$ & $186(55.5)$ & $1.213(0.934-1.576)$ & $1.306(0.975-1.751)$ \\
\hline C allele & 979 (69.9) & $436(65.1)$ & 1.00 (reference) & 1.00 (reference) \\
\hline $\begin{array}{l}\text { G allele } \\
\text { rs11137037 }\end{array}$ & $421(30.1)$ & $234(34.9)$ & $1.248(1.026-1.518)^{*}$ & $1.314(1.057-1.634)^{*}$ \\
\hline AA & 354 (50.6) & $122(36.4)$ & 1.00 (reference) & 1.00 (reference) \\
\hline AC & $240(34.3)$ & $139(41.5)$ & $1.681(1.253-2.253)^{*}$ & $1.653(1.193-2.289)^{*}$ \\
\hline CC & $106(15.1)$ & $74(22.1)$ & $2.026(1.412-2.907)^{*}$ & $2.039(1.367-3.040)^{*}$ \\
\hline $\mathrm{AC}+\mathrm{CC}$ & $346(49.4)$ & $213(63.6)$ & $1.786(1.367-2.344)^{*}$ & $1.777(1.320-2.392)^{*}$ \\
\hline A allele & $948(67.7)$ & $383(57.2)$ & 1.00 (reference) & 1.00 (reference) \\
\hline $\begin{array}{l}\mathrm{C} \text { allele } \\
\text { rs12674822 }\end{array}$ & $452(32.3)$ & $287(42.8)$ & $1.572(1.300-1.900)^{*}$ & $1.577(1.276-1.949)^{*}$ \\
\hline GG & $243(34.7)$ & $62(18.5)$ & 1.00 (reference) & 1.00 (reference) \\
\hline GT & 301 (43.0) & $175(52.2)$ & $2.279(1.629-3.187)^{*}$ & $2.422(1.674-3.506)^{*}$ \\
\hline TT & $156(22.3)$ & $98(29.3)$ & $2.462(1.690-3.587)^{*}$ & $2.250(1.481-3.420)^{*}$ \\
\hline $\mathrm{GT}+\mathrm{TT}$ & 457 (65.3) & $273(81.5)$ & $2.341(1.706-3.213)^{*}$ & $2.368(1.670-3.359)^{*}$ \\
\hline $\mathrm{G}$ allele & 787 (56.2) & $299(44.6)$ & 1.00 (reference) & (reference) \\
\hline $\mathrm{T}$ allele & $61.3(43.8)$ & $371(55.4)$ & $1.593(1.324-1.917)^{*}$ & $1.514(1.232-1.861)^{*}$ \\
\hline
\end{tabular}

Table 3. Odds ratios (ORs) and $95 \%$ confidence intervals $(\mathrm{Cls})$ of the clinical status and genotype frequencies of the Ang2 rs 12674822 polymorphism in 335 patients with RA.

\begin{tabular}{|c|c|c|c|c|}
\hline \multirow[t]{2}{*}{ Variable } & \multicolumn{4}{|c|}{ Genotypic frequencies } \\
\hline & $\begin{array}{l}\text { G allele } \\
\mathrm{N}=299 \\
(\%)\end{array}$ & $\begin{array}{l}\mathrm{T} \text { allele } \\
\mathrm{N}=371 \\
(\%)\end{array}$ & $\begin{array}{l}\text { OR } \\
(95 \% \mathrm{CI})\end{array}$ & $\begin{array}{l}\text { AOR } \\
(95 \% \mathrm{CI})\end{array}$ \\
\hline \multicolumn{5}{|l|}{ RF status } \\
\hline Negative & 49 (16.4) & $57(15.4)$ & 1.00 (reference) & 1.00 (reference) \\
\hline Positive & $250(83.6)$ & $314(84.6)$ & $1.080(0.712-1.637)$ & $1.080(0.712-1.638)$ \\
\hline \multicolumn{5}{|l|}{ ACPA status } \\
\hline Negative & $55(18.4)$ & $73(19.7)$ & 1.00 (reference) & 1.00 (reference) \\
\hline Positive & $244(81.6)$ & $298(80.3)$ & $0.920(0.624-1.357)$ & $0.915(0.619-1.352)$ \\
\hline \multicolumn{5}{|l|}{$\begin{array}{l}\text { Anti-TNF drugs } \\
\text { use }\end{array}$} \\
\hline Non-users & $173(57.9)$ & $233(62.8)$ & 1.00 (reference) & 1.00 (reference) \\
\hline Current users & $126(42.1)$ & $138(37.2)$ & $0.813(0.596-1.110)$ & $0.814(0.596-1.111)$ \\
\hline \multicolumn{5}{|c|}{ Methotrexate use } \\
\hline Non-users & $153(51.2)$ & $187(50.4)$ & 1.00 (reference) & 1.00 (reference) \\
\hline Current users & $146(48.8)$ & $184(49.6)$ & $1.031(0.760-1.398)$ & $1.026(0.754-1.396)$ \\
\hline \multicolumn{5}{|c|}{ Prednisolone use } \\
\hline Non-users & $152(50.8)$ & $160(43.1)$ & 1.00 (reference) & 1.00 (reference) \\
\hline
\end{tabular}

\begin{tabular}{lllll}
\hline Variable & \multicolumn{4}{l}{ Genotypic frequencies } \\
& $\begin{array}{l}\text { G allele } \\
\mathrm{N}=299\end{array}$ & $\begin{array}{l}\mathrm{T} \text { allele } \\
\mathrm{N}=371 \\
(\%)\end{array}$ & $\begin{array}{l}\text { OR } \\
(\mathbf{9 5} \% \mathrm{CI})\end{array}$ & $\begin{array}{l}\text { AOR } \\
(\mathbf{9 5} \% \mathrm{CI})\end{array}$ \\
& $\mathbf{( \% )}$ & & \\
\hline Current users & $147(49.2)$ & $211(56.9)$ & $\mathbf{1 . 3 6 4}$ & $\mathbf{1 . 3 6 2}$ \\
& & & $(\mathbf{1 . 0 0 4 - 1 . 8 5 2})^{*}$ & $(\mathbf{1 . 0 0 3 - 1 . 8 5 0 )}$ \\
\hline
\end{tabular}

The odds ratios (ORs) and their $95 \%$ confidence intervals (CIs) were estimated by logistic regression models. The adjusted odds ratios (AORs) with their 95\% CIs were estimated by multiple logistic regression analyses that controlled for gender. $* p<0.05$ as statistically significant.

$\mathrm{RA}=$ rheumatoid arthritis; $\mathrm{RF}=$ rheumatoid factor; $\mathrm{ACPA}=$ anti-citrullinated protein antibodies; $\mathrm{TNF}=$ tumor necrosis factor.

Table 4. Comparison of the clinical parameters and genotype frequencies of the Ang2 rs734701 polymorphism in 335 patients with RA.

\begin{tabular}{llll}
\hline Parameter & \multicolumn{1}{c}{ C allele $(\mathbf{N = 5 7 2})$} & T allele $(\mathbf{N = 9 8})$ & \\
\cline { 2 - 3 } & Mean \pm S.E.M. & & p value \\
\hline RA duration (months) & $69.88 \pm 5.34$ & $80.04 \pm 14.07$ & 0.262 \\
Serum CRP (mg/L) & $21.95 \pm 4.32$ & $18.14 \pm 3.86$ & 0.566 \\
ESR (mm/h) & $31.76 \pm 1.45$ & $37.88 \pm 4.50$ & $\mathbf{0 . 0 0 6 *}$
\end{tabular}

Independent sample $t$ test was used to make comparisons between clinical parameters and the $\mathrm{C}$ and $\mathrm{T}$ alleles of the Ang $2 \mathrm{rs} 734701$ polymorphisms. ${ }^{*} p \leq 0.05$ was considered to be significant.

RETN = resistin; RA = rheumatoid arthritis; RA = rheumatoid arthritis; S.D. = standard deviation; $\mathrm{CRP}=\mathrm{C}$-reactive protein, $\mathrm{ESR}=$ erythrocyte sedimentation rate.

Table 5. Comparison of the clinical parameters and genotype frequencies of the Ang2 rs 11137037 polymorphism in 335 patients with RA.

\begin{tabular}{|c|c|c|c|}
\hline \multirow[t]{2}{*}{ Parameter } & A allele $(\mathrm{N}=522)$ & $\mathrm{C}$ allele $(\mathrm{N}=148)$ & \multirow[b]{2}{*}{ p value } \\
\hline & \multicolumn{2}{|c|}{ Mean \pm S.E.M. } & \\
\hline \multicolumn{4}{|c|}{ RA duration (months) } \\
\hline & $75.30 \pm 6.04$ & $57.47 \pm 7.41$ & $0.003^{*}$ \\
\hline \multicolumn{4}{|c|}{ Serum CRP (mg/L) } \\
\hline & $22.12 \pm 4.67$ & $18.81 \pm 3.81$ & 0.508 \\
\hline \multicolumn{4}{|c|}{$\operatorname{ESR}(\mathrm{mm} / \mathrm{h})$} \\
\hline & $32.06 \pm 1.57$ & $34.76 \pm 3.13$ & 0.378 \\
\hline
\end{tabular}

Independent sample $\mathrm{t}$ test was used to make comparisons between clinical parameters and the A and C alleles of the Ang 2 rs 11137037 polymorphisms. ${ }^{*} p \leq 0.05$ was considered to be significant.

RETN = resistin; $\mathrm{RA}$ = rheumatoid arthritis; $\mathrm{RA}=$ rheumatoid arthritis; S.D. = standard deviation; $\mathrm{CRP}=\mathrm{C}$-reactive protein, $\mathrm{ESR}=$ erythrocyte sedimentation rate.

\section{Discussion}

The RA susceptibility is influenced by genetic factors. Although the advent of biological-based antirheumatic therapies has enabled some patients to achieve very low levels of disease activity, there are still an unignorable number of RA patients who remain treatment-refractory $[1,25,26]$. The unmet need underlines the importance of continuing to investigate the pathogenesis of RA. Genetic studies indicate that specific SNPs are associated with the RA risk [27]. The search for RA-related SNPs seems to be a promising method to understand the pathogenesis of RA and for risk stratification [28].

Ang2 has been shown to be involved in the pathogenesis of RA. VEGF-induced Ang2 is the main 
regulator in the IL-35 suppressed RA angiogenesis [29]. The serum level of Ang2 correlates with disease severity, early onset and cardiovascular disease among RA patients [30]. The bispecific TNF- $\alpha$-Ang2 molecules showed a dose-dependent reduction in both clinical RA symptoms and histological scores that were significantly better than that achieved by adalimumab alone in mouse RA model [31]. Krausz et al. identified synovial macrophages as primary targets of Ang signaling in RA, and demonstrated that Ang2 promotes the pro-inflammatory activation of human macrophages. The authors thus suggested that targeting Ang2 may be of therapeutic benefit in the treatment of RA [32]. These findings suggest that Ang2 can be enlisted among the factors that dictate the pathogenesis of RA.

The Ang2 SNPs possess prognostic values for various human diseases. The Ma's study proposed Ang2 gene as a susceptibility gene for neovascular age-related macular degeneration and polypoidal choroidal vasculopathy [20]. The rs2442598 polymorphism of Ang2 gene was significantly associated with psoriasis vulgaris [33]. Genetic variants in the Ang2 gene are associated with increased risk of acute respiratory distress syndrome [17].

Despite the evidence inferring a role for Ang2 in the pathogenesis of RA and the prognostic capacity of Ang2 SNPs in various human diseases, few studies have investigated the relationship between Ang2 SNPs and risk of developing RA. Previous studies have been reported the role of Ang1 was involved in RA [34, 35]. However, none of studies explored the correlation between Ang2 gene polymorphism and RA progression. In this study, we sought to determine the prognostic capacity of Ang2 SNPs in predicting RA onset. To the best of our knowledge, our study is the first to identify that the distribution of rs2442598, rs734701, rs1823375, rs11137037 and rs12674822 SNPs is associated with RA development. We examined five Ang2 SNPs among 700 controls and 335 RA patients. We found that when compared with the subjects with the A/A genotype of SNP rs2442598, the subjects with the $\mathrm{T} / \mathrm{T}$ genotype were 1.78 times likely to develop RA. The subjects with $\mathrm{C} / \mathrm{C}$ genotype of SNP rs734701 were 0.53 times likely to develop RA than the subjects with TT genotype, suggesting the protective effect. The subjects with G/G genotype of SNP rs1823375 were 1.77 times likely to develop RA than the subjects with $\mathrm{C} / \mathrm{C}$ genotype. The subjects with $\mathrm{A} / \mathrm{C}$ and $\mathrm{C} / \mathrm{C}$ genotype of SNP rs11137037 were 1.65 and 2.04 times likely to develop RA than the subjects with A/A genotype. The subjects with G/T and T/T genotype of SNP rs12674822 were 2.42 and 2.25 times likely to develop RA than the subjects with
G/G genotype. These findings have not been reported up to now. We also investigated the association of these Ang2 SNPs with RA treatment regimens and serum inflammatory markers. We found that Ang2 rs11137037 had a high risk in RA patients which correlated with ESR. Although rs734701 had a protective effect, it was associated with clinical ESR of RA patients. These correlations between clinical results and genetic function required to be further explored in the future. On the other hands, our linkage disequilibrium analysis had no significant results between these Ang2 SNPs (Supplement Fig. S1).

A major limitation to this study is that the findings of our study might be mere cross-relationship instead of actual causality. This is a ubiquitous limitation for similar studies and might be partially overcome by the deeper evaluation trying to select and analyze the relationships between all the known SNP elements. In conclusion, our study offers novel insights into Ang2 SNPs in regard to RA susceptibility. We found that the A/A genotype of SNP rs2442598, G/G genotype of SNP rs1823375, A/C and C/C genotype of SNP rs11137037, and GT and TT genotype of SNP rs12674822 were associated with higher risk for RA development, and C/C genotype of SNP rs734701 was associated with decreased RA risk. This is the first study to demonstrate that a correlation exists between Ang2 polymorphisms and RA risk. Ang2 might be a diagnostic marker and therapeutic target for RA therapy. Therapeutic agents that directly or indirectly modulate the activity of Ang2 may be the promising modalities for RA treatment.

\section{Supplementary Material}

Supplementary figure.

http://www.medsci.org/v16p0331s1.pdf

\section{Acknowledgments}

This work was supported by grants from China's National Natural Science Foundation (No. 81702117), and Taiwan's Ministry of Science and Technology (MOST107-2320-B-039-019-MY3; 107-2314-B-039-064-) and China Medical University (CMU107-BC-5).

\section{Competing Interests}

The authors have declared that no competing interest exists.

\section{References}

1. Kuo SJ, Huang CC, Tsai CH, et al. Chemokine C-C Motif Ligand 4 Gene Polymorphisms Associated with Susceptibility to Rheumatoid Arthritis. Biomed Res Int. 2018; 2018: 9181647.

2. Chen $\mathrm{CY}, \mathrm{Su} \mathrm{CM}, \mathrm{Hsu} \mathrm{CJ}$, et al. CCN1 Promotes VEGF Production in Osteoblasts and Induces Endothelial Progenitor Cell Angiogenesis by Inhibiting miR-126 Expression in Rheumatoid Arthritis. J Bone Miner Res. 2017; 32: 34-45. 
3. Gabriel SE, Crowson CS, O'Fallon WM. Mortality in rheumatoid arthritis: have we made an impact in 4 decades? J Rheumatol. 1999; 26: 2529-33.

4. Kuo CF, Luo SF, See LC, et al. Rheumatoid arthritis prevalence, incidence, and mortality rates: a nationwide population study in Taiwan. Rheumatol Int. 2013; 33: 355-60.

5. Su CM, Huang CY, Tang $\mathrm{CH}$. Characteristics of resistin in rheumatoid arthritis angiogenesis. Biomark Med. 2016; 10: 651-60.

6. Wang LH, Wu MH, Chen PC, et al. Prognostic significance of high-mobility group box protein 1 genetic polymorphisms in rheumatoid arthritis disease outcome. Int J Med Sci. 2017; 14: 1382-1388.

7. Suzuki A, Yamamoto K. From genetics to functional insights into rheumatoid arthritis. Clin Exp Rheumatol. 2015; 33: S40-3.

8. Wang $\mathrm{L}$, Tang $\mathrm{CH}, \mathrm{Lu} \mathrm{T}$, et al. Resistin polymorphisms are associated with rheumatoid arthritis susceptibility in Chinese Han subjects. Medicine (Baltimore). 2018; 97: e0177.

9. Huang BF, Tzeng HE, Chen PC, et al. HMGB1 genetic polymorphisms are biomarkers for the development and progression of breast cancer. Int J Med Sci. 2018; 15: 580-586.

10. Wang CQ, Tang $\mathrm{CH}$, Chang HT, et al. Fascin-1 as a novel diagnostic marker of triple-negative breast cancer. Cancer Med. 2016; 5: 1983-8.

11. $\mathrm{Li} \mathrm{TC}$, Li CI, Liao LN, et al, Associations of EDNRA and EDN1 polymorphisms with carotid intima media thickness through interactions with gender, regular exercise, and obesity in subjects in Taiwan: Taichung Community Health Study (TCHS). Biomedicine (Taipei). 2015; 5: 8.

12. Paleolog EM. Angiogenesis in rheumatoid arthritis. Arthritis Res. 2002; 4 Suppl 3: S81-90.

13. Su CM, Hsu CJ, Tsai CH, et al. Resistin Promotes Angiogenesis in Endothelial Progenitor Cells Through Inhibition of MicroRNA206: Potential Implications for Rheumatoid Arthritis. Stem Cells. 2015; 33: 2243-55.

14. Liu SC, Chuang SM, Hsu CJ, et al. CTGF increases vascular endothelial growth factor-dependent angiogenesis in human synovial fibroblasts by increasing miR-210 expression. Cell Death Dis. 2014; 5: e1485.

15. MacDonald IJ, Liu SC, Su CM, et al. Implications of Angiogenesis Involvement in Arthritis. Int J Mol Sci. 2018; 19.

16. Gao W, Sweeney C, Walsh C, et al. Notch signalling pathways mediate synovial angiogenesis in response to vascular endothelial growth factor and angiopoietin 2. Ann Rheum Dis. 2013; 72: 1080-8.

17. Su L, Zhai $\mathrm{R}$, Sheu CC, et al. Genetic variants in the angiopoietin-2 gene are associated with increased risk of ARDS. Intensive Care Med. 2009; 35: 1024-30.

18. Wang LH, Tsai HC, Cheng YC, et al. CTGF promotes osteosarcoma angiogenesis by regulating miR-543/angiopoietin 2 signaling. Cancer Lett. 2017; 391: 28-37.

19. Fagiani E, Christofori G. Angiopoietins in angiogenesis. Cancer Lett. 2013; 328: 18-26.

20. Ma L, Brelen ME, Tsujikawa M, et al. Identification of ANGPT2 as a New Gene for Neovascular Age-Related Macular Degeneration and Polypoidal Choroidal Vasculopathy in the Chinese and Japanese Populations. Invest Ophthalmol Vis Sci. 2017; 58: 1076-1083

21. Meyer NJ, Li M, Feng R, et al. ANGPT2 genetic variant is associated with trauma-associated acute lung injury and altered plasma angiopoietin-2 isoform ratio. Am J Respir Crit Care Med. 2011; 183: 1344-53.

22. Miaskowski C, Dodd M, Paul SM, et al. Lymphatic and angiogenic candidate genes predict the development of secondary lymphedema following breast cancer surgery. PLoS One. 2013; 8: e60164.

23. Wang B, Hsu CJ, Chou CH, et al. Variations in the AURKA Gene: Biomarkers for the Development and Progression of Hepatocellular Carcinoma. Int J Med Sci. 2018; 15: 170-175

24. $\mathrm{Hu}$ GN, Tzeng HE, Chen PC, et al. Correlation between CCL4 gene polymorphisms and clinical aspects of breast cancer. Int J Med Sci. 2018; 15: 1179-1186.

25. Hu SL, Chang AC, Huang CC, et al. Myostatin Promotes Interleukin-1beta Expression in Rheumatoid Arthritis Synovial Fibroblasts through Inhibition of miR-21-5p. Front Immunol. 2017; 8: 1747.

26. Tsai CH, Liu SC, Wang YH, et al. Osteopontin inhibition of miR-129-3p enhances IL-17 expression and monocyte migration in rheumatoid arthritis. Biochim Biophys Acta Gen Subj. 2017; 1861: 15-22.

27. Yamamoto K, Okada Y, Suzuki A, et al. Genetic studies of rheumatoid arthritis. Proc Jpn Acad Ser B Phys Biol Sci. 2015; 91: 410-22.

28. Viatte S, Barton A. Genetics of rheumatoid arthritis susceptibility, severity, and treatment response. Semin Immunopathol. 2017; 39: 395-408.

29. Jiang $\mathrm{S}, \mathrm{Li} \mathrm{Y}, \mathrm{Lin} \mathrm{T}$, et al. IL-35 Inhibits Angiogenesis through VEGF/Ang2/Tie2 Pathway in Rheumatoid Arthritis. Cell Physiol Biochem. 2016; 40: 1105-1116

30. Lopez-Mejias R, Corrales A, Genre F, et al. Angiopoietin-2 serum levels correlate with severity, early onset and cardiovascular disease in patients with rheumatoid arthritis. Clin Exp Rheumatol. 2013; 31: 761-6.

31. Kanakaraj P, Puffer BA, Yao XT, et al. Simultaneous targeting of TNF and Ang2 with a novel bispecific antibody enhances efficacy in an in vivo model of arthritis. MAbs. 2012; 4: 600-13.

32. Krausz S, Garcia S, Ambarus CA, et al. Angiopoietin-2 promotes inflammatory activation of human macrophages and is essential for murine experimental arthritis. Ann Rheum Dis. 2012; 71: 1402-10.

33. He L, Dang L, Zhou J, et al. Association of angiopoietin-1, angiopoietin-2 and caspase- 5 polymorphisms with psoriasis vulgaris. Clin Exp Dermatol. 2015; 40: 556-63.
34. Thompson SD, Sudman M, Ramos PS, et al. The susceptibility loci juvenile idiopathic arthritis shares with other autoimmune diseases extend to PTPN2, COG6, and ANGPT1. Arthritis Rheum. 2010; 62: 3265-76.

35. Shiozawa $\mathrm{S}$, Komai $\mathrm{K}$, Kawasaki $\mathrm{H}$, et al. The molecular genetics of rheumatoid arthritis disease gene. Nihon Rinsho. 2002; 60: 2269-75. 